\title{
RELATIONSHIP BETWEEN ANALOGIC VISUAL SCALE FOR FEAR OF MOVEMENT AND TAMPA SCALE OF KINESIOPHOBIA APPLIED IN PATIENTS AND BREAST CANCER SURVIVORS
}

Vitor Marques'1, Wanderson Santos¹, Naiany Silva1', Raquel Schincaglia², Carlos Vieira'

${ }^{1}$ Faculty of Physical Education and Dance, Universidade Federal de Goiás - Goiânia (GO), Brazil.

${ }^{2}$ Faculty of Nutrition, Universidade Federal de Goiás - Goiânia (GO), Brazil.

Purpose: The aim of this study is to verify if there is a relationship between the Analogic Visual Scale (AVS; 0-10) for fear of movement and the Tampa Scale of Kinesiophobia (TSK) in patient/survivors with breast cancer. Methodology: Twentyfour women with breast cancer (age: 52.29 \pm 8.28 years, range: 35-64 years) attended a single day of evaluation. The fear of movement was assessed by the two psychometric measurements as follows: (1) AVS, a metric rule printed with a scale ranging from 0 ("not afraid at all") to $100 \mathrm{~mm}$ ("complete afraid") for using the ipsilateral limb affected by the surgical and (2) TSK, the total score ranging from 17 to 68. TSK with higher scores represents the increasing of the kinesiophobia. The TSK was transformed to the same range scale as AVS, in which 17 is 0 and 68 is 100, for comparison. The relationship between AVS and TSK was investigated with a linear regression analysis. The variability between scales was tested using the coefficient of variation (CV). Results: We did not find a relationship between AVS and TSK $\left(\mathrm{r}=0.008, \mathrm{R}^{2}<0.0001, \mathrm{p}=0.971\right)$. The CV was $56.52 \% \pm 47.51 \%$, with $95 \% \mathrm{CI}$ ranging from 36.45 to 76.58 . Conclusion: There is no relationship between AVS and TSK; hence, they should not be used interchangeably to measure the fear of movement. Therefore, general kinesiophobia may not represent the specific kinesiophobia in women with breast cancer.

Keywords: Breast Cancer; Kinesiophobia; Psychometric. 